\title{
Vincent Laisney, L'Arsenal romantique. Le salon de Charles Nodier (1824-1834)
}

\section{Lise Sabourin}

\section{(2) OpenEdition}

1 Journals

\section{Édition électronique}

URL : http://journals.openedition.org/studifrancesi/27717

DOI : $10.4000 /$ studifrancesi. 27717

ISSN : 2421-5856

Éditeur

Rosenberg \& Sellier

\section{Édition imprimée}

Date de publication : 31 décembre 2006

Pagination : 615-616

ISSN : 0039-2944

\section{Référence électronique}

Lise Sabourin, «Vincent Laisney, L'Arsenal romantique. Le salon de Charles Nodier (1824-1834) 》, Studi Francesi [En ligne], 150 (L | III) | 2006, mis en ligne le 30 novembre 2015, consulté le 08 novembre 2020. URL : http://journals.openedition.org/studifrancesi/27717 ; DOI : https://doi.org/10.4000/ studifrancesi.27717

Ce document a été généré automatiquement le 8 novembre 2020.

\section{(c) $(1) \odot$}

Studi Francesi è distribuita con Licenza Creative Commons Attribuzione - Non commerciale - Non opere derivate 4.0 Internazionale. 


\title{
Vincent Laisney, L'Arsenal romantique. Le salon de Charles Nodier (1824-1834)
}

\author{
Lise Sabourin
}

\section{RÉFÉRENCE}

VINCENT LAISNEY, L'Arsenal romantique. Le salon de Charles Nodier (1824-1834), avec une présentation de Bernard LEULLIOT, Paris, Honoré Champion, «Romantisme et modernités», n 49, 2002, pp. XIII-836.

1 L'exploration des milieux littéraires est toujours à enrichir: tous savent l'importance du salon tenu à partir de 1824 par le conservateur de l'Arsenal, Nodier, avec l'aide de sa femme, puis de sa fille. Mais l'ouvrage de Vincent Laisney permet d'en connaître à fond le fonctionnement, les membres habitués ou occasionnels, les liens selon leurs typologies, les grandes entreprises comme les faiblesses, la place dans les combats et les mouvements du temps. Cette décennie de "camaraderie littéraire», selon l'expression de Latouche, de «soirées artistes» dans l'entrecroisement merveilleux de richesse des poètes, peintres et musiciens, fait émerger de la foule des minores les «royautés littéraires» dénoncées en 1834 par Planche, après la politisation progressive jusqu'à 1830 et le désenchantement de 1832. Surtout ce travail remet en question nos catégorisations, pratiques mais souvent artificielles, comme le souligne son préfacier, Bernard Leuilliot: au terme de l'«analyse des 'rites de sociabilité du salon de l'Arsenal', de ses 'structures communautaires' et de ses 'courants idéologiques et esthétiques'» (p. $\mathrm{XIII}$ ), l'on découvre que «le romantisme n'existe pas» (Laisney, p. 805). Non point qu'il n'y ait des romantiques, un esprit romantique, une littérature romantique, mais parce que, dans ce vivier, Nodier réunit des «ethnies» différentes, avec chacune son «patois», dans une grande liberté de rencontre, en refus du débat imposé de l'extérieur par les attaques contre ces jeunes gens de la «décadence» (selon le terme de Nisard), qui ne cherchent pourtant qu'à renouveler l'écriture de leur sensibilité! Il faudra en 1843 
presque déjà que son ancien hôte meure pour que «l'enfant du siècle» fasse de Nodier le «père du romantisme».

2 En contact permanent avec les autres cercles, salons et cénacles parisiens, l'Arsenal se veut profondément hétérogène par la diversité de ses invités; si Désirée puis Marie constituent le pivot originel aux côtés de Charles Nodier, l'ellipse peut aussi choisir d'autres cœurs du foyer en Hugo, Dumas ou Musset au fil des évolutions ou bifurcations de sa trajectoire, d'abord religieuse, puis plus esthétique, enfin métaphysique ou sociale. Quand l'éclatement menace, au reflux saint-simonien et par la diaspora des Jeunes-France, la «boutique romantique» ferme ses portes, mais l'aventure collective a porté ses fruits, qu'un temps nouveau récusera sans pour autant en détruire en soi l'héritage, quitte à le faire fructifier tout autrement. Le carrefour entre tradition et modernité qu'a incarné cette forme cénaculaire en gestation, évoluant d'une mondanité aristocratique vers une sociabilité artistique et conviviale, a manifesté l'esprit de liberté propre à la génération de 1830, lui a donné des repères sans entraves, dans cette arche providentielle entretenue par le maître de maison, accueillant aux talents supérieurs comme aux "petits auteurs», dans un esprit démocratique où la solidarité n'exclut pas la possibilité d'être différent, par une pratique orale de la littérature qui fonctionne comme une «répétition théâtrale de l'œuvre» (pp. 807) à écrire.

3 Les sept parties de l'ouvrage assurent la connaissance progressive de l'Arsenal, «de la simple peinture des 'dimanches' à l'analyse de [son] système de pensée» (pp. 24-25). Après une description des rites de sociabilité (souper, causerie, lecture, danse..., pp. 29-135), V.Laisney répartit les invités en fonction de leur importance et de leur nature: hommes essentiels par leur influence, leur rayonnement au sein du salon ou leur relation privilégiée avec l'hôte, notamment prééminence de Hugo (pp. 137-246); places respectives de Vigny, Lamartine, Musset, Sainte-Beuve, Dumas, Balzac, Gautier et Nerval (pp. 259-376); effets de groupes des membres moins connus, parisiens ou provinciaux (pp. 377-475), envisagés selon leurs origines géographiques, sociales ou professionnelles (Bisontins, journalistes, éditeurs et directeurs de revues, artistes en quête de rencontres avec les poètes, femmes écrivains, pp. 477-597). Puis il analyse les systèmes d'entraide caractéristiques du salon (pp. 599-686) et ses divers courants de pensée, souvent volatiles et éphémères plutôt que doctrinaux (pp. 689-798).

C'est ainsi qu'outre sa localisation, le titre de l'ouvrage trouve sa pleine justification de «chantier» du romantisme, par le "dépôt» d'opinions et d'idées laissé par chacun, mais aussi en offrant un «matériel» complexe d'hommes, de convictions et de théories souvent divergentes, liés pourtant par la cohérence de leur fréquentation. Une somme donc, après les livres de Bernard Degout sur Le Sablier retourné. Victor Hugo et le débat sur le romantisme (1816-1824) (Champion, 1998, pp. 763) et de Patrick Besnier sur Mallarmé et le théâtre de la rue de Rome (Éditions du Limon, 1998, pp. 101): cette thèse comble une lacune dans l'histoire littéraire du siècle et invite à entreprendre des travaux similaires sur les autres milieux de la Monarchie de Juillet et du Second Empire. 